\title{
Ações afirmativas: uma análise do acesso e da permanência dos alunos cotistas do IFSul
}

\section{Positive actions: an analysis of admission and permanence of IFSul balancing students}

\section{Políticas de acción afirmativa: un análisis de la admisión y de la permanência de los estudiantes titulares de cuotas del IFSul}

\author{
Márcia Helena Sauaia Guimarães Rostas* \\ Maria Cecilia Isaacsson ${ }^{* *}$ \\ Rafael Montoito***
}

\section{Resumo}

O presente trabalho é resultado de uma dissertação que analisou o ingresso por cotas nos cursos técnicos de nível médio da forma integrada do Instituto Federal de Educação, Ciência e Tecnologia Sul-rio-grandense (IFSul), campus Pelotas, e o quadro geral dos alunos cotistas no que tange às políticas de ações afirmativas de permanência e ao êxito escolar. Para tal, utilizamos como metodologia o estudo de caso e a análise de categorias referentes ao recebimento ou não de benefícios oferecidos pela instituição, com abordagem qualitativa (estudo dos referenciais teóricos acerca da temática) e quantitativa (análise dos dados sistêmicos). Quanto à coleta de dados, usamos pesquisa bibliográfica, extração de dados sistêmicos e aplicação de questionário ao universo de alunos que ingressaram em 2014/1. Ao final, concluímos que as cotas podem promover uma "pseudo" mobilidade social e que o aluno que ingressa por este sistema não vincula a isso sua permanência ou êxito escolar.

Palavras-chave: Educação. Êxito escolar. Ingresso por Cotas. Permanência. Políticas Afirmativas.

Recebido em 25/02/2020 - Aprovado em 05/10/2020

http://dx.doi.org/10.5335/rep.v27i3.12384

Graduada em Pedagogia pela universidade Federal do Maranhão; especialista em magistério superior pelo Centro Universitário do Maranhão; Mestre em Economia pela universidade Federal e de Pernambuco; Doutora em Linguística e Língua Portuguesa pela Universidade Estadual Paulista Julio de Mesquita Filho - Unesp - Araraquara. Professora no programa de pós-graduação em Educação do Instituto Federal de Educação, Ciência e Tecnologia Sul-rio-grandense. Orcid: https://orcid.org/0000-0003-4949-0023

** Graduada em Direito pela Universidade Católica de Pelotas (UCPel); Licenciada em Formação Docente para a Educação Básica - Letras pela Faculdade Educacional da Lapa; Especialista em Direito Civil e Processual Civil pela Faculdade Anhanguera Pelotas; Mestre em Educação e Tecnologia pelo Instituto Federal de Educação, Ciência e Tecnologia Sul-rio-grandense (IFSul); Doutoranda em Educação e Tecnologia no Instituto Federal de Educação, Ciência e Tecnologia Sul-rio-grandense (IFSul). Orcid: https://orcid.org/0000-0002-1128-3857

*** Graduado em Matemática pela Universidade Federal de Pelotas; Mestre em Ciências Sociais Aplicadas pela Universidade Federal do Rio Grande do Norte; Doutor em Educação para a Ciência pela Universidade Estadual Paulista Julio de Mesquita Filho - Unesp - Bauru. Professor no programa de pós-graduação em Educação do Instituto Federal de Educação, Ciência e Tecnologia Sul-rio-grandense. Orcid: https://orcid.org/0000-0002-3294-3711 


\section{Abstract}

This study originated in a dissertation that analyzed racial balancing through the high school technical program integrated modality admission at Instituto Federal de Educação, Ciência e Tecnologia Sul-rio-grandense (IFSul), Pelotas Campus, and the racial balancing student general Picture regarding positive action policies of attendance and academic achievement. For such, case study methodology and the analysis of categories referring to the receipt or not of benefits offered by the institution were used with both qualitative (theoretical references studies on the subject) and quantitative (systemic data analysis) approaches. As for data collection, bibliographic research and systemic data extraction were used, as well as a questionnaire was applied to the universe of students who joined the institution in 2014/1. At the end, it was concluded that racial balancing can promote a \&quot;pseudo\&quot; social mobility, and that joining the institution through this system does not necessarily guarantee attendance or academic achievement.

Keywords: Education. Academic Achievement. Racial Balancing Admission. Attendance. Positive Policies.

\section{Resumen}

El presente trabajo es el resultado de una tesis de maestría en la que se analizó la admisión por cuotas en los cursos técnicos de la forma integrada a la enseñanza media del Instituto Federal de Educação, Ciência e Tecnologia Sul-rio-grandense (IFSul), campus Pelotas, y el panorama general de los estudiantes titulares de cuotas con respecto a las políticas de acción afirmativa de permanencia y éxito escolar. Para ello, utilizamos como metodología el estudio de caso y el análisis de categorías relacionadas con la recepción o no de los beneficios ofrecidos por la institución, con enfoque cualitativo (estudio de referencias teóricas sobre el tema) y cuantitativo (análisis de datos sistémicos). A respeto de la recopilación de datos, utilizamos la investigación bibliográfica, la extracción de datos sistémicos y la aplicación de un cuestionario al universo de estudiantes que ingresaron en 2014/1. Al final, concluimos que las cuotas pueden promover una "pseudo" movilidad social y que el estudiante que ingresa a través de este sistema no vincula su permanencia o éxito en la escuela a eso.

Palabras clave: Educación. Éxito escolar. Admisión por Cuotas. Permanencia. Políticas Afirmativas.

\section{Introdução}

As políticas sociais adotadas no Brasil objetivam assegurar a todos os cidadãos o acesso à melhoria de qualidade de vida, o que inclui aí diversos aspectos como saúde, segurança, seguridade social e educação. Tais políticas vêm promovendo, desta forma, a inclusão dos cidadãos de todas as esferas sociais e, em especial, os menos favorecidos que, independente do motivo, não foram inseridos no contexto em decorrência de algum "artifício" de exclusão social.

Nessa linha, a reserva de vagas para acesso à educação pública, discutida na pesquisa cujos resultados aqui trazemos, bem como a implantação de políticas de permanência na escola, serviram de parâmetro para a análise das políticas afirmativas adotadas pelo governo, por meio das instituições públicas de educação, com intuito de garantir a educação, prevista constitucionalmente. Os relatos e análises 
que comentaremos a seguir, sobre esta temática, tiveram como cenário o campus Pelotas do Instituto de Educação, Ciência e Tecnologia Sul-rio-grandense (IFSul).

Nosso escopo principal era verificar o alcance de algumas políticas educacionais, tendo em vista que o simples ingresso na instituição pública de ensino não garante o efetivo acesso e permanência do cidadão na escola, como mostra o elevado índice de evasão escolar. A partir dessa observação, questionamo-nos sobre a importância da implementação do programa de assistência estudantil e se, para os alunos que o recebem, é este um diferencial que os auxilia a permanecer na instituição e concluir o curso de sua opção.

O Departamento de Gestão de Assistência Estudantil (DEGAE) do IFSul possui dados ${ }^{1}$ que nos remetem ao pensamento de que as políticas públicas estão obtendo resultados: $80 \%$ dos alunos beneficiários dos auxílios estudantis conseguiram superar os desafios encontrados na trajetória educacional. No entanto, sem desconsiderar a importância e relevância dos auxílios prestados pela AE (Assistência Estudantil), ressaltamos que não é necessário que o aluno tenha ingressado por meio da política de reserva de vagas para dela ter direito, embora acreditemos que dificilmente o aluno que ingresse pela reserva de vagas não se utilize desses auxílios.

Considerando que a última pesquisa sobre os impactos dos auxílios estudantis realizada no IFSul, pelo DEGAE, se deu em 2015, os dados coletados nessa pesquisa por meio de dados sistêmicos e questionário podem servir de subsídios para nova pesquisa referente aos auxílios e análise dos impactos institucionais dos auxílios nas questões de permanência e êxito no IFSul.

As questões que levantamos dirigem, então, um olhar mais específico ao grupo de alunos que ingressou na instituição por uma reserva de vagas. A reserva de determinada porcentagem das vagas, especificamente para o ingresso ao ensino no IFSul, campus Pelotas, garantiu o acesso, permanência e a formação do sujeito/ cidadão que se enquadra nas condições previstas em lei específica? Até onde essa política afirmativa de reserva de vagas, para ingresso na instituição de ensino, assegurou a igualdade de direitos prevista constitucionalmente, além de gerar um índice positivo de permanência e êxito escolar?

Em um país com tamanhas e notórias desigualdades sociais, a política educacional tem buscado medidas compensatórias aos eleitos, por ela, como mais frágeis em detrimento de outros que, a seus olhos, não preenchem os requisitos necessários. Nossa discussão parte do momento em que os alunos ganham acesso à escola 
para tentar desvendar se há, e quais, relações entre a reserva de vagas e os índices de permanência, evasão e êxito dos alunos do IFSul, campus Pelotas.

\section{Ações afirmativas, acesso e permanência escolares: um olhar sobre esses conceitos}

A ideia da pesquisa nasceu a partir de uma inquietação acerca da efetividade e do alcance da política pública de reserva de vagas para o ingresso no ensino público (Lei $\mathrm{n}^{\mathrm{o}}$ 12.711, de 29 de agosto de 2012, regulamentada pelo Decreto $\mathrm{n}^{\mathrm{o}}$ 7.824, de 11 de outubro de 2012), em especial nos cursos técnicos de ensino médio na forma integrada do IFSul.

Passamos a nos questionar se a utilização de cotas para acesso ao ensino técnico de nível médio contribuiu, de alguma forma, além das ações afirmativas promovidas pela instituição, para a permanência e para o êxito do aluno. E, ainda, de forma suplementar e não menos importante, se há algum reflexo nos índices de evasão.

Há inúmeras discussões na sociedade, algumas favoráveis e outras não, referentes ao ingresso por cotas nas instituições de ensino públicas. Dada a essa dicotomia que transparece nos discursos da sociedade, percebemos que pesquisar essa política de ingresso por cotas e suas peculiaridades constituía-se uma temática de grande relevância que, de alguma forma, merecia uma reflexão mais apurada.

Optamos por realizar a pesquisa no nível médio técnico ${ }^{2}$ tendo em vista que a lei que regulamenta o acesso ao ensino por cotas é do ano de 2012 e, portanto, em função do pouco tempo decorrido, ainda não teríamos, no ensino superior, alunos egressos para a pesquisa. Desta forma, não seria possível verificar índice de êxito escolar ${ }^{3}$ desses alunos ou, até mesmo, questões referentes à permanência ${ }^{4}$ de maneira mais aprofundada. Levamos, para tanto, em consideração as formas de ensino técnico de nível médio ofertadas no IFSul (Integrado, Concomitante e Subsequente), observando que o sujeito que ingressa em um curso técnico de nível médio na forma integrada é proveniente diretamente do ensino fundamental, o que o faz frequentar tão logo o ensino médio e um curso técnico à sua escolha. Dessa forma, ele está mais ligado à instituição que os alunos das formas Concomitante e Subsequente, motivo que justifica a escolha deste grupo de alunos para serem o sujeito da nossa investigação. Além disso, dentre o grupo de alunos do ensino técnico de nível médio de forma integrada, interessava-nos olhar aquele que optou 
por utilizar uma forma diferenciada de acesso à escola, o ingresso por cotas, necessitando ou não de ações de permanência para continuar e concluir o estudo de nível médio/técnico.

Na dissertação Ações Afirmativas em foco: uma análise do acesso e da permanência de alunos cotistas do IFSul - Campus Pelotas, a partir da qual foi feito esse recorte, existe um estudo mais aprofundado, em um capítulo nominado "Estado da Questão", no qual foi feito um levantamento dos trabalhos até então publicados sobre a temática.

Em um primeiro momento, determinamos os tipos de trabalhos que seriam mapeados nos bancos de dados, delimitando em artigos, dissertações e teses. Os repositórios utilizados foram: a Comissão de Aperfeiçoamento de Pessoal de Nível Superior (Capes), o Instituto Brasileiro de Informação em Ciência e Tecnologia - IBICT a partir do Banco Digital de Teses e Dissertações (BDTD) e a Scientific Electronic Library Online (SciELO), por se constituírem, entre outras, em fontes com credibilidade e aquiescência na comunidade acadêmica. Utilizamos as palavras-chave conforme Quadro 1, no período dos anos de 2005 a $2016^{5}$ :

Quadro 1 - Resultado da busca em repositórios

\begin{tabular}{|c|c|c|c|c|c|c|c|c|c|c|c|c|c|}
\hline $\begin{array}{l}\text { Palavras-chave: Cotas; } \\
\text { permanência; políticas } \\
\text { afirmativas; educação. }\end{array}$ & ஜ̊ํ & ஜ̊ & 옹 & 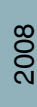 & : & 웅 & $\bar{\Sigma}$ & $\frac{N}{\sim}$ & $\stackrel{m}{\infty}$ & $\frac{\nabla}{\infty}$ & $\frac{10}{\delta}$ & $\frac{0}{\stackrel{\alpha}{\alpha}}$ & $\begin{array}{l}\bar{\pi} \\
\text { 으 }\end{array}$ \\
\hline Artigos científicos & $x$ & 2 & $\mathrm{x}$ & 3 & $x$ & $x$ & $x$ & 4 & 1 & 2 & 1 & $\mathrm{x}$ & 13 \\
\hline Dissertações & 1 & $x$ & 1 & $x$ & 1 & 1 & 2 & $x$ & 1 & 2 & 2 & 1 & 12 \\
\hline Teses & $x$ & $x$ & 1 & 1 & 1 & 1 & $x$ & $x$ & $\mathrm{x}$ & $x$ & $x$ & $x$ & 04 \\
\hline Total geral & 1 & 2 & 2 & 4 & 2 & 2 & 2 & 4 & 2 & 4 & 3 & 1 & 29 \\
\hline
\end{tabular}

Fonte: elaboração dos autores.

Selecionamos, então, alguns trabalhos para uma leitura mais detalhada sobre o tema. Utilizamos como critérios de seleção a semelhança com o tema abordado. Assim, os trabalhos que trataram sobre as políticas afirmativas de acesso, e, principalmente de políticas de permanência dos estudantes nas instituições de ensino, se tornaram o foco desta etapa. Os parâmetros de escolha dos trabalhos incidiram na convergência de abordagem aspirada para esta pesquisa, tendo sido agrupados, de acordo com o Quadro 2, a seguir: 
Quadro 2 - Resultado final das pesquisas para análise

\begin{tabular}{|c|c|c|c|c|c|c|c|c|c|c|c|c|c|}
\hline & \multicolumn{13}{|c|}{ Anos } \\
\hline Tipos & 옹 & $\begin{array}{l}\ell \\
\text { ¿ }\end{array}$ & 유 & $\begin{array}{l}\infty \\
\varnothing \\
\varnothing\end{array}$ & 。 & c & $\bar{c}$ & cे & $\frac{m}{\infty}$ & $\frac{\nabla}{\circ}$ & $\frac{10}{\delta}$ & $\frac{0}{\stackrel{N}{ }}$ & $\begin{array}{l}\bar{\sigma} \\
\stackrel{0}{0}\end{array}$ \\
\hline Artigos científicos & $x$ & 1 & $\mathrm{X}$ & 1 & $x$ & $x$ & $x$ & 1 & 1 & 1 & 0 & $\mathrm{X}$ & 5 \\
\hline Dissertações & 0 & $\mathrm{X}$ & 1 & $\mathrm{X}$ & 1 & 0 & 0 & $x$ & 0 & 0 & 1 & 1 & 4 \\
\hline Teses & $x$ & $\mathrm{X}$ & 0 & 0 & 1 & 0 & $x$ & $x$ & $\mathrm{X}$ & $\mathrm{x}$ & $\mathrm{X}$ & $\mathrm{X}$ & 1 \\
\hline Total geral & 0 & 1 & 1 & 1 & 2 & 0 & 0 & 1 & 1 & 1 & 1 & 1 & 10 \\
\hline
\end{tabular}

Fonte: elaboração dos autores.

A busca e o breve relato das 10 publicações (entre artigos, dissertações e tese) foram feitos com o intuito de, além de servir de base a esta pesquisa (no campo metodológico e teórico), situar nós e o leitor na perspectiva e relevância do objeto que nos propomos investigar.

Ainda existe muita discussão no que se refere às ações afirmativas no campo da permanência dos alunos cotistas. A maioria delas demonstrou haver restrições às ações de permanência, sendo vinculadas apenas à assistência estudantil e/ou bolsas de auxílio. Nesse passo, são poucas ou subjetivas as questões que tratam de ações afirmativas inovadoras.

Os trabalhos relacionados no Estado da Questão da dissertação deram conta de trazer à tona a importância dada, pelas instituições, em primeiro garantir o acesso para, apenas posteriormente, refletir sobre as questões de permanência. Ademais, demonstraram a relevância de considerar as dificuldades, dilemas, superações dos alunos que ingressaram pelas cotas.

Trouxeram, também, a importância de verificação das razões de necessidade de ações para a redução de distâncias sociais, ressaltando as cotas não como mecanismo de disparidade, e sim como meio de justiça social.

Quando fazemos a vinculação dos conceitos sobre ações afirmativas, questões alusivas ao acesso e permanência, com os trabalhos analisados na Dissertação, podemos perceber, inicialmente, que a temática de cotas no ensino médio, em cursos técnicos da forma integrada, não é alvo de muitos estudos. Em verdade, o que mais vemos são as cotas para acesso e permanência no ensino superior, mas em nada se opõe a fazermos uma comparação aos cursos de ensino médio. 
A legislação que trata sobre cotas obriga as instituições de ensino a fazerem uso dessa sistemática. Parece-nos que a preocupação com a educação segue por parte do governo, tanto que houve ampliação das cotas, agora para incluir as pessoas com deficiência, conforme alteração feita pela Portaria Normativa $n^{\circ} 9$, de 05/05/2017 do MEC. No entanto, essa preocupação com a inclusão e a universalização do ensino esbarra em algumas medidas tomadas pelo governo.

Trazendo à baila o fato de o Brasil passar constantemente por mudanças bruscas no que diz respeito à Educação, observamos a aprovação da Proposta de Emenda Constitucional (PEC) 241/2016, mais conhecida no âmbito da educação como "PEC da morte", já que congela gastos com investimentos na educação da população Brasileira. Aprovada, passou a ser chamada como Emenda Constitucional no 95/2016, e trata especificamente da instituição de um novo regime fiscal, a partir do qual os gastos com saúde, educação, etc. passam a ter um teto.

Considerando que esse regime fiscal tem o prazo de 20 anos de vigência, sendo esse o tempo considerado necessário para que a dívida pública fique estagnada ou, como no próprio texto diz, "permaneça em um patamar seguro", com a devida vênia, ao limitar os gastos com a educação (que acreditamos já serem insuficientes), a situação precária das escolas pode ser afetada.

Inferimos, no que diz respeito ao acesso dos estudantes, que poderemos ter um "caos" quando, por conta dessa falta de investimento, o número de vagas ofertadas for reduzido e, por consequência disso, o ingresso a alunos cotistas passe a ser limitado.

A própria intenção da criação da cota, no sentido de universalizar o acesso à educação, fica prejudicada na medida em que não há interesse que a população que mais precisa tenha acesso à educação pública quando não se tem investimento nessa área.

Concordamos com Charlot (2005, p. 131), que o modo de articulação entre a escola e a sociedade se tornou um meio de garantir uma boa carreira profissional:

[...] a possibilidade de encontrar um "bom emprego" (interessante, bem pago, bem situado na hierarquia social) depende do nível de êxito na escola. Por consequência, esse êxito é um ponto de passagem obrigatório para se ter uma vida "normal" e, ainda mais, para se beneficiar de uma ascensão social. Em outras palavras, é sua vida futura que os jovens jogam na escola".

Arriscamos dizer que um sistema educacional, como o do Brasil, que funciona de forma gradual e progressiva, que passa por inúmeras e constantes dificuldades e barreiras impostas pela falta de investimento do Estado, principalmente com as 
limitações orçamentárias em decorrência da EC 95/2016, não se sustenta. Como um país, sem incentivo financeiro, fiscal e orçamentário à educação pode propor um ensino integral sem sequer suprir as deficiências básicas das escolas? Inferimos que as políticas de ações afirmativas podem vir a sofrer cortes prejudicando uma educação pública, de qualidade, tornando ineficaz a universalização da educação, deixando aos jovens pouco espaço para uma formação continuada e de qualidade, que não seja pura e simplesmente para torná-lo uma mão de obra barata com um "sucesso" inverídico.

A própria ideia da cota, no sentido de universalizar o acesso à educação, fica prejudicada na medida em que não há interesse que a população que mais precisa tenha acesso à educação pública quando não se tem investimento nessa área.

Não obstante, temos que a questão da permanência como uma política afirmativa é um processo em construção, sendo necessário realizar um estudo específico em um universo determinado. Nesse sentido, nossa pesquisa buscou levantar dados e discutir a questão do acesso e, principalmente, da permanência dos alunos cotistas no IFSul, para que, ao final, possamos refletir sobre ações que previnam a evasão e/ou retenção. Para esta análise, usamos por parâmetro os alunos ingressantes no IFSul campus Pelotas, na forma integrada, com matrícula referente ao período letivo 2014/1.

Para entender esse cenário sobre como vem acontecendo o acesso aos cursos técnicos da forma integrada do IFSul campus Pelotas, via reserva de vagas (cotas), bem como para aprofundar uma reflexão acerca das relações entre as políticas de ações afirmativas e permanência desses alunos, julgamos necessário, neste momento, trazer à tona alguns conceitos e problematizações.

\section{Sobre ações afirmativas e políticas públicas}

Para Gomes (2002, p. 128-129), as ações afirmativas definem-se como:

[...] políticas públicas (e privadas), voltadas à concretização do princípio constitucional da igualdade material e à neutralização dos efeitos da discriminação racial, de gênero, de idade, de origem nacional e de compleição física. [...] a igualdade deixa de ser simplesmente um princípio jurídico a ser respeitado por todos e passa a ser um objetivo constitucional a ser alcançado pelo Estado e pela sociedade.

Sob a ótica do autor, as ações afirmativas podem ser de caráter compulsório, facultativo ou voluntário, e são concebidas com vistas a combater diversos tipos de discriminação (racial, de gênero, por deficiência física e de origem nacional) e a 
corrigir ou mitigar os efeitos presentes da discriminação herdada do passado, com o objetivo principal de concretizar do ideal de efetiva igualdade de acesso a bens fundamentais como a educação e o emprego. Gomes (2003) ainda afirma que é preciso conscientizar a sociedade e a classe política para que trabalhem no intuito de minimizar as desigualdades, levando em consideração que "a marginalização socioeconômica a que são relegadas as minorias, especialmente as raciais, resulta de um único fenômeno: a discriminação" (GOMES, 2005, p. 52).

Conceitos parecidos trazem Piovesan e Fonseca. Para o primeiro, as ações afirmativas são medidas especiais e temporárias que, "buscando remediar um passado discriminatório, objetivam acelerar o processo de igualdade, com o alcance da igualdade substantiva por parte de grupos socialmente vulneráveis, como as minorias étnicas e raciais, entre outros grupos" (PIOVESAN, 2005, p. 41); já para o outro, elas são “destinadas a atender grupos sociais que se encontrem em condições de desvantagem ou vulnerabilidade social em decorrência de fatores históricos, culturais e econômicos" (FONSECA, 2009, p. 11).

É importante discorrermos sobre o conceito de políticas públicas também, já que as ações afirmativas nada mais são do que um tipo de política pública adotada pelo Estado. Nesse espaço, tomamos por definição de política pública a trazida por Amabile (2012, p. 390), que estabelece como sendo:

[...] decisões que envolvem questões de ordem pública com abrangência ampla e que visam à satisfação do interesse de uma coletividade. Podem também ser compreendidas como estratégias de atuação pública, estruturadas por meio de um processo decisório composto de variáveis complexas que impactam na realidade.

Com base nesses conceitos, podemos afirmar que as ações afirmativas se constituem em um instrumento de correção por meio de condutas e normas propostas pelo "Estado", no sentido de recuperar direitos fundamentais de pessoas que se encontram em desvantagem e/ou desigualdade social por decorrência de algum tipo de discriminação (econômica, racial, política, etc.). Desta forma, toda ação afirmativa - que em nossa pesquisa é a reserva de vagas para ingressar na instituição - objetiva garantir a igualdade e a isonomia entre as pessoas. Comentaremos adiante, mais detalhadamente, se estes objetivos foram alcançados para um grupo diferenciado de estudantes, foco do nosso trabalho. 


\section{Sobre 0 acesso à educação na legislação brasileira}

Para começarmos a falar do acesso à educação a partir de políticas afirmativas, é necessário fazermos a distinção entre os termos acesso e ingresso, visto que a legislação e a literatura que trata das políticas inclusivas utiliza-se ora de um termo, ora de outro. O ingresso do aluno se concretiza com a matrícula na instituição após o processo seletivo. Já o acesso, uma designação que consideramos mais ampla, abrange tanto o ingresso na instituição quanto a participação deste indivíduo nas ações promovidas pela e na escola. Seria, nesta perspectiva, o sentir-se incluído no ambiente educacional, como parte do processo de formação. Em outras palavras, além do simples ingresso por algum tipo de cota, o acesso é o reconhecimento deste indivíduo como integrante daquele lugar.

Com relação ao acesso à educação, consta na Constituição Federal $(\mathrm{CF})$ de 1988, lei maior do país, que ela é um direito e garantia fundamental do cidadão. O artigo $6^{\circ}$ descreve que são direitos sociais "a educação, a saúde, a alimentação, o trabalho, a moradia, o transporte, o lazer, a segurança, a previdência social, a proteção à maternidade e à infância, a assistência aos desamparados, na forma desta Constituição" (BRASIL, 1988, não paginado).

Com base nesse direito, garantido pela $\mathrm{CF}$, é que se sustenta toda a legislação que rege o acesso à educação, sendo dever do Estado, como declarado no artigo 208, garantir a educação básica obrigatória e gratuita assegurando, inclusive, sua oferta gratuita "para todos os que a ela não tiveram acesso na idade própria; [...] O acesso ao ensino obrigatório e gratuito é direito público subjetivo" (BRASIL, 1988, não paginado).

A Lei de Diretrizes e Bases da Educação Nacional (LDB) - Lei no 9.394/1996 - estabelece as diretrizes e bases da educação no Brasil e, portanto, disciplina a educação escolar, a partir de então. Dentre os seus princípios aponta, no artigo $3^{\text {o }}$ inciso I, a igualdade de condições para o acesso e permanência na escola. A garantia de acesso e permanência passou a ser regida por dispositivos legais e, assim, objetiva a universalização da educação.

O termo universalização da educação nos remete à ideia de tornar a educação mais acessível às classes populares, ao alcance do povo, da maioria da população, não se confundindo com o conceito de Educação Popular, o que poderia indicar uma educação de menor qualidade. Fernandes e Luft (2005) tratam o termo "universalizar" como um sinônimo de "generalizar, espalhar-se, difundir-se". Partindo desta 
terminologia podemos acrescer, de forma complementar, a ideia de universalismo, defendida por Ivo (2013, p. 528), que o caracteriza como:

[...] [um] paradigma [...] segundo o qual se considera que todos os cidadãos, sem distinção de classe ou posição no mercado, têm direito a serviços sociais que respondam aos princípios democráticos de igualdade de direitos e de status e que garantam os mesmos benefícios sociais e os mesmos padrões de qualidade a todos e cada um dos cidadãos no âmbito dos sistemas de bem-estar.

Desta forma o dispositivo legal subsidia o princípio de popularizar a educação possibilitando o alcance a um número maior de pessoas. A LDB, por conseguinte, garante o ingresso por meio da criação de formas de acesso alternativas, com a intenção de garantir o ensino a todos, de democratizar a educação propriamente dita. Porém, na prática, reconhecemos a dificuldade no atendimento à totalidade das pessoas em idade escolar. A lei, em seu art. $5^{\circ}$, estabelece que o acesso à educação básica obrigatória é direito público subjetivo.

Por se tratar de uma instituição federal de ensino, o acesso a todos os cursos ofertados pelo IFSul ocorre por meio de processo seletivo. Estes se dão, de forma distinta, pelo nível de ensino: processo seletivo próprio, para ingresso nas formas integrada, concomitante e subsequente ao ensino médio e pós-graduação; e Exame Nacional do Ensino Médio (Enem) ou Sistema de Seleção Unificada (SiSU), para ingresso nos cursos superiores. Realizado duas vezes ao ano, uma no inverno e outra no verão, o processo seletivo próprio é gratuito a todos os candidatos. A disponibilidade das vagas é apontada pelo plano de vagas disponibilizado por cada campus.

O ingresso dos candidatos pode se dar pelo Acesso Universal (AU) ou, ainda, pela Reserva de Vagas para Egressos de Escolas Públicas (RVEEP), sendo que, em todos os cursos ofertados na instituição, $50 \%$ das vagas são destinadas à RVEEP, atendendo o IFSul à implementação de políticas de ações afirmativas.

O candidato que deseja ingressar via reserva de vagas/cotas deverá se declarar integrante de um dos quatro grupos descritos no edital no 191/2013 do IFSul, baseado na Portaria Normativa $n^{\circ}$ 18/2012, que consideram a renda bruta familiar, sua etnia e onde realizaram seus estudos do ensino fundamental. Na nossa pesquisa, colhemos os dados dos alunos que se encaixavam no grupo L4, ou seja, os candidatos autodeclarados pretos, pardos ou indígenas que, independente da renda, tenham cursado integralmente o ensino fundamental em escola pública ${ }^{7}$ (IFSUL, 2013). 
O amparo legal dessa forma de ingresso (reserva de vagas) fundamenta-se, além dos direitos e garantias constitucionais, na Lei $\mathrm{n}^{\circ}$ 12.711, de 29 de agosto de 2012. Pauta-se, ainda, na portaria normativa $\mathrm{n}^{\circ} 18$ de 2012, do Ministério da Educação (MEC), que dispõe sobre a implementação dessa reserva de vagas em instituições federais de ensino, bem como no Decreto no 7.824, de 11 de outubro de 2012 , que a regulamenta.

\section{Sobre a permanência escolar}

A legislação estabelece, em seu artigo 206, inciso I, que não basta garantir o acesso para que o aluno alcance a efetiva educação, mas é necessário que lhe seja oportunizada a permanência na escola (BRASIL, 1988), assim, poderá vir a ter êxito no ensino. Para entendermos melhor essa questão trazemos, primeiramente, o conceito de "permanência" que, segundo o do dicionário on-line Michaelis é o "ato de permanecer; o estado ou a qualidade de permanente; constância, perseverança". Entendemos, portanto, como conceito básico de permanência escolar o ato do aluno perseverar, continuar e não desistir de seus estudos. Compreendemos, ainda, a "permanência e êxito" escolar, como o ato de ingressar, acessar e permanecer na escola até concluir, com êxito, o curso no qual o aluno ingressou, ressaltando o caráter temporal do prazo estipulado para integralização do seu estudo.

Logo, não há como seguir discorrendo sobre permanência sem entendermos, também, o conceito de evasão, já que os alunos que não permanecem estudando são considerados evadidos. $\mathrm{O}$ mesmo dicionário on-line define evasão como sendo a "ação ou processo de evadir, de deliberadamente fugir" e isso, por conseguinte, conduz à compreensão de que a evasão é um processo de desistência, por parte do aluno, da escola.

De acordo o artigo 74 da Organização Didática da Educação Básica, Profissional e Superior de Graduação do IFSul (OD) ${ }^{8}$, é considerado evadido o estudante que estiver em um destes dois grupos: ou ele apresenta índice de frequência inferior a 50\% do total da carga horária do período e nota zero (ou conceito equivalente em todas as disciplinas na última etapa de avaliação, caso a avaliação não se dê numericamente), ou ele não efetua a renovação de matrícula nos prazos definidos no calendário acadêmico. Em qualquer um destes casos, o estudante evadido perde o direito à sua vaga.

Assim, com intuito de cumprir disposições legais, o ministério da Educação criou o Programa de Acolhimento, Permanência e Êxito (PAPE), instituído pela portaria 
interministerial $n^{\circ}$ 04, de 06 de maio de 2016. Neste programa são expressos direitos e garantias constitucionais, como o dever do Estado com a educação em todas as etapas da educação básica, as formas de colaboração para assegurar a universalização do ensino obrigatório, o cumprimento das metas do Plano Nacional de Educação (PNE), a importância de ações integradas entre educação, assistência social e saúde, e a intersetorialidade na execução de programas como o Saúde na Escola, o Bolsa Família e o Benefício de Prestação Continuada na Escola, dentre outros.

O PAPE tem por finalidade “desenvolver ações [...] que promovam a busca e o retorno às escolas das crianças, adolescentes e jovens que, em idade escolar, não foram matriculadas nas redes públicas", e prevê o desenvolvimento de ações integradas "como forma de reduzir a evasão escolar e ampliar as possibilidades de conclusão com êxito da educação básica” (MEC, 2016).

Ao buscarmos as ações de permanência que já existem no campus, nos deparamos, primeiramente, com a previsão, no regimento interno do campus Pelotas, da responsabilidade de "fomentar e promover, em conjunto com os demais profissionais da educação, ações para permanência e êxito do estudante" da Coordenadoria de Assistência Estudantil (COAE). Esta coordenadoria obedece ao disposto no regimento interno do campus.

Ao aprofundarmos um pouco mais a busca sobre a autoria da responsabilidade de ações que promovam a permanência dos estudantes, encontramos, no Regimento $\mathrm{Geral}^{9}$ do IFSul, o Departamento de Políticas Educacionais como o responsável pela proposição de estratégias e projetos institucionais para permanência e êxito dos estudantes; a Pró-Reitoria de Extensão e Cultura como a responsável pela contribuição para o acesso e permanência e êxito de pessoas com deficiência e de grupos sociais que são alvo de políticas públicas afirmativas; e o Departamento de Educação Inclusiva que tem como uma de suas atribuições divulgar os objetivos das ações inclusivas, motivando o acesso, a permanência e o êxito de pessoas que se encontram em situação de vulnerabilidade social. Verificamos, ainda, que a Política de Assistência Estudantil (PAE) ${ }^{10}$ vem sendo implantada desde 2010 no IFSul. Este documento nos traz um conjunto de princípios e diretrizes que norteiam a implementação de ações que tem como objetivo promover o acesso, a permanência e o êxito dos alunos sob a ótica da equidade entre outras.

Identificamos, também, a Câmara de Assistência Estudantil ${ }^{12}$ como um órgão consultivo e propositivo com o objetivo de cooperar para a integração dos campi do IFSul. Este órgão busca o aperfeiçoamento e desenvolvimento dos temas relacionados à Assistência Estudantil. 
Ainda, embora sua publicação (2017) tenha sido posterior à esta pesquisa, trazemos, para conhecimento do leitor, o Plano Estratégico Institucional de Permanência e Êxito dos Estudantes do IFSul ${ }^{12}$, que possui como objetivo geral promover, por meio de ações sistêmicas e locais articuladas, a permanência e o êxito dos estudantes do IFSul. Dentre seus objetivos específicos estão os de fomentar a problematização da qualidade e efetividade das diversas ofertas educativas dos variados campi do IFSul, com vistas ao controle e à gradual redução dos fatores de evasão e retenção do Instituto; construir diagnóstico quali-quantitativo acerca dos fenômenos "evasão" e "retenção" no âmbito dos diferentes campi e cursos do IFSul; planejar e implementar estratégias de redução e controle das interveniências individuais, institucionais e socioculturais que impactam os índices de evasão e retenção nos diversos cursos e campi do IFSul; e deflagrar ações sistêmicas e locais para a promoção da permanência e êxito dos estudantes, tendo em vista os fatores convergentes detectados nos variados cenários de evasão e retenção diagnosticados nos campi do IFSul.

Além desses supracitados, verificamos a implementação de programas assistenciais para a permanência neste ambiente, como é o caso do Plano Nacional de Assistência Estudantil (PNAES), previsto no Decreto nํㅜ 7.234/2010, o qual objetiva melhorar as condições de permanência e êxito dos estudantes em situação de vulnerabilidade social a partir da alocação de recursos financeiros para atender as demandas da Assistência Estudantil.

O campus Pelotas, espaço no qual foi desenvolvida a pesquisa, atualmente conta, no que tange a ações que visam o acesso e a permanência dos estudantes, com políticas adotadas pela Coordenadoria Assistência Estudantil (COAE), a qual oferece benefícios aos alunos, tais como transporte urbano, transporte intermunicipal, alimentação (almoço e/ou jantar), auxílio moradia e auxílio material escolar. A estes benefícios, que são oferecidos por meio de Editais, publicados com periodicidade semestral, soma-se a oferta da COAE, estendida a todos os alunos do campus, de acompanhamento psicológico. Segundo consta na descrição do serviço de psicologia ${ }^{13}$, este é um instrumento importante que "visa promover ações nas áreas de saúde; desenvolver atividades de orientação profissional; e fomentar e promover, em conjunto com os demais profissionais da educação, ações para a permanência e êxito dos estudantes" e seus ecos perpassam ações vinculadas ao ensino (incluídas aí questões ligadas à aprendizagem), à pesquisa e à extensão.

Dentro deste ambiente da COAE há, ainda, o Núcleo de Apoio às Pessoas com Necessidades Específicas (NAPNE), responsável pela preparação da instituição 
no acolhimento de pessoas cegas, surdas-mudas, deficientes físicos, dentre outros. Sendo assim, é um núcleo que trabalha com políticas inclusivas para garantir o acesso, a permanência e o êxito do estudante.

Outras ações relevantes do campus que repercutem na permanência discente, no combate à evasão e na retenção são os editais para processos seletivos de alunos para bolsas de monitorias para Cursos Técnicos de Nível Médio e a oferta de atendimento médico e odontológico (o que também se estende aos servidores). Embora esta segunda não esteja vinculada diretamente à COAE, estando este setor ligado diretamente ao Gabinete do Diretor Geral do campus, ela não pode ficar de fora daquilo que chamamos de benefícios, já que a consideramos um auxílio aos alunos que, se por vezes não têm condições de arcar com os custos desses serviços essenciais à saúde e ao seu bem-estar, têm acesso a eles na escola. Reconhecendo que tais serviços são imprescindíveis para o bom andamento acadêmico dos alunos, analisamos sua importância no questionário aplicado.

\section{Descrição da pesquisa: da coleta de dados à interpretação dos resultados}

Nosso intento de pesquisa versou sobre a forma como vem ocorrendo o acesso aos cursos da forma integrada do IFSul campus Pelotas, por meio de reserva de vagas (cotas) e quais são as políticas de ações afirmativas de permanência desses alunos. Ainda, de qual forma são propostas e como o estudante se utiliza dessas ações e se tem alguma contribuição na sua elaboração. No tocante ao índice de evasão, nos disponibilizamos a verificar se é alto entre os cotistas e quais motivos ensejaram a evasão.

Para situar o leitor, trazemos um pequeno histórico da instituição pesquisada: o Instituto Federal de Ensino, Ciência e Tecnologia Sul-rio-grandense faz parte de uma Rede Federal de Educação Profissional e Tecnológica, proveniente do antigo CEFET-RS, e instituído pela Lei no 11.892, de 29 de dezembro de 2008. Atualmente, o IFSul é composto por 14 campi, conforme Figura 1, a seguir, e pela Reitoria, que se localiza também em Pelotas (RS), juntamente com os campi Pelotas e Pelotas-Visconde da Graça. 
Figura 1 - Distribuição dos campi do IFSul

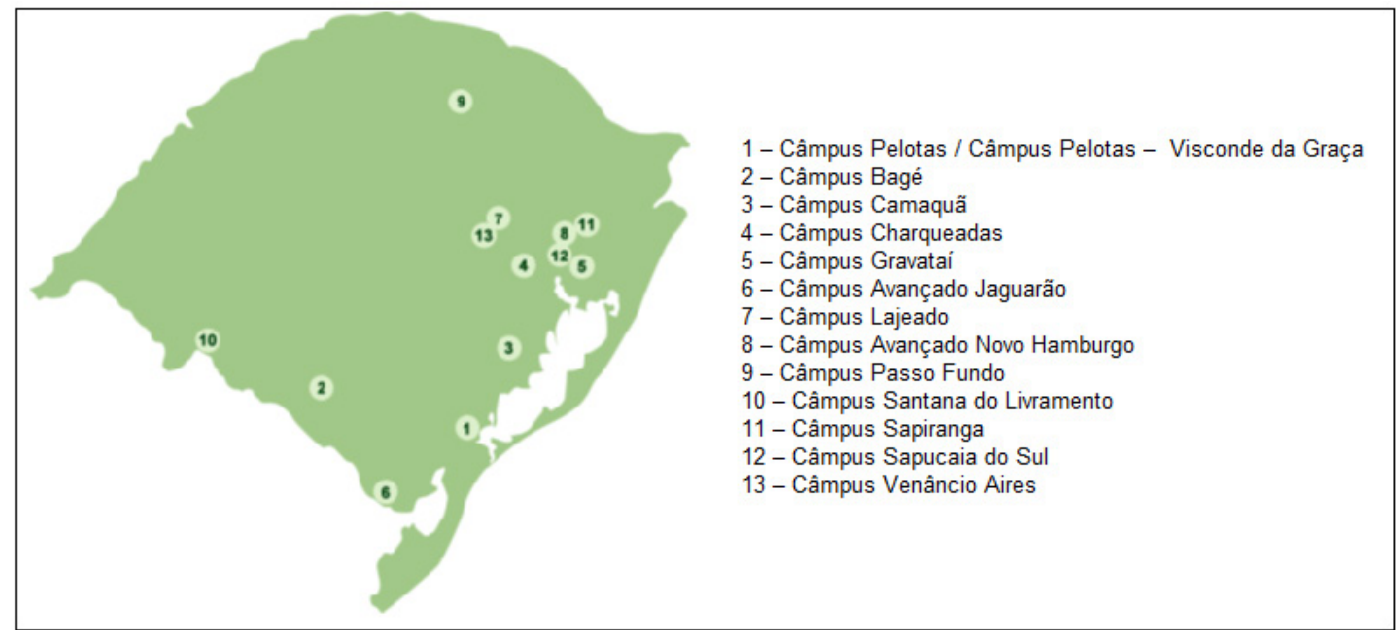

Fonte: Instituto Federal Sul-rio-grandense ${ }^{14}$.

O espaço de nossa pesquisa ficou, então, delimitado ao campus Pelotas, situado na cidade de Pelotas (RS), pela proximidade e consequente facilidade na coleta de informações, sendo que utilizamos também como balizador a forma integrada de nível médio, restringindo o período ao primeiro processo seletivo em que foi disponibilizada a reserva de vagas no IFSul.

Ainda, para a percepção do leitor de como ocorreu a aplicação do sistema de cotas no IFSul, ressaltamos que o debate sobre a questão iniciou em 2012, quando a Lei que rege o tema passou a vigorar. Logo, em 2013, quando lançado o Edital para ingresso via processo seletivo no IFSul para o ano letivo de 2014, a instituição aderiu à proposta legislativa fazendo, com isso, valer o dispositivo legal.

Estando definida a investigação, optamos pela pesquisa qualitativa com nuances quantitativas no que se refere aos percentuais a serem levantados. Sobre a pesquisa qualitativa, Denzin e Lincoln elucidam que "é uma atividade situada que localiza o observador no mundo" e nos permite compreender as questões envolvidas no universo da pesquisa com maior profundidade (DENZIN; LINCOLN, 2006, p. 17).

As nuances quantitativas a que nos referimos anteriormente se deram com a coleta de dados no sistema Q-acadêmico ${ }^{15}$ a partir dos quais, tabulados percentualmente, pudemos verificar o desempenho no acesso e no rendimento escolar obtido pelos alunos. 
A pesquisa desenvolveu-se sob os preceitos de um Estudo de Caso, que é um "método de olhar a realidade social" (GOODE; HATT, 1968, p. 421), que realiza uma investigação empírica acerca de um fenômeno contemporâneo, tomado em profundidade e em seu contexto de mundo real (YIN, 2015), o que nos permitiu entender algumas questões abarcadas no contexto social dos alunos que acessam e permanecem, com ou sem êxito escolar, além de verificar as causas da evasão escolar.

Ressaltamos que a análise dos dados e do questionário foi feita através da construção de categorias referentes ao recebimento ou não de benefícios oferecidos pela instituição. Em um primeiro momento, tivemos contato com documentos escolares dos alunos e suas respostas aos questionários para, após isso, refletir sobre o material e apresentar uma interpretação dos resultados obtidos.

\section{Da coleta de dados e das categorias}

Com base no sistema Q-Seleção, também utilizado pelo IFSul, o processo seletivo de candidatos para o período letivo de 2014/01 teve, de modo geral, 3.457 alunos inscritos em cursos técnicos integrados para o campus Pelotas sendo que, desse total, confirmaram a sua inscrição para participar da seleção 2.495 candidatos. Dos confirmados, apenas 45 candidatos se inscreveram para concorrer pela cota L4, e apenas 20 alunos se matricularam como cotistas L4 após o processo seletivo de ingresso.

Após a coleta de dados no sistema Q-Acadêmico, identificamos o universo de 20 alunos que correspondiam ao nosso interesse de pesquisa. Com as informações extraídas do sistema, em um primeiro momento, pudemos listar os seus dados pessoais (e-mail e telefone) e, por meio de comunicação via e-mail, propusemos a aplicação de um questionário elaborado com dados necessários para a investigação. Após duas semanas, não obtivemos nenhuma resposta dos alunos que ingressaram por cotas no ano de 2014/1. Tal situação ensejou que fôssemos em busca desses alunos de forma mais incisiva e diferenciada, já que suas respostas eram fundamentais para as análises e conclusões desta pesquisa.

Desta forma, como estratégia inicial de alcance, buscamos, junto ao Departamento de Ensino da escola, os dados dos 13 alunos que permaneciam matriculados (07, dos 20 ingressantes, haviam evadido). Depois de localizar as turmas nas quais teriam aulas, fomos pessoalmente ter uma conversa com eles sobre a importância da pesquisa e da sua participação e lhes explicamos que os resultados seriam apre- 
sentados à escola como forma de instrumentar mecanismos de melhoria tanto para o acesso quanto para a permanência dos alunos cotistas. Mesmo assim, apenas 09 alunos nos enviaram, posteriormente, suas respostas.

Em relação aos 07 evadidos, tentamos um novo contato via e-mail. Não obtivemos nenhum retorno e, assim, inovamos na forma de abordagem, chamando-os a responder o nosso instrumento de pesquisa de maneira mais informal, via redes sociais como Facebook e WhatsApp, mas apenas 01 aluno nos deu retorno.

Nossa amostra, que ao final reduziu-se a um total de 10 alunos (09 regulares e 01 evadido), representava 50\% do universo de ingressantes pela cota L4 sendo, portanto, um número significativo para subsidiar a pesquisa, pois Marconi e Lakatos (2005) alertam que, normalmente, os questionários enviados têm uma taxa de devolução de, em média, $25 \%$.

Esses 10 alunos pesquisados foram separados, segundo suas respostas, em dois grupos, "A" e "B". O grupo "A" foi formado por alunos que, devidamente matriculados, utilizavam ou já tinham utilizado qualquer benefício/auxílio da Assistência Estudantil (AE); no grupo "B" ficaram os alunos que nunca tinham utilizado nenhum benefício/auxílio da AE. Ficaram no grupo "A" 03 alunos (todos regulares) e, no "B", 07 alunos (06 regulares e 01 evadido).

Na sequência, em relação ao grupo "A", foi aplicado um questionário cujo intuito era verificar as condições de acesso e o perfil destes alunos (renda familiar e declaração de etnia, bem como o alcance da política de cotas). Concomitantemente, em relação ao grupo "B", foi aplicado o mesmo instrumento, haja vista a peculiaridade de ingresso por cota e não utilização de benefícios da Assistência Estudantil, o que por si só caracteriza uma situação excepcional.

A partir disso, alinhavamos as intenções de coletas de dados com categorias construídas, utilizando-se da Análise de Conteúdo, com a intenção de mapear a relação entre o ingresso por cotas com a permanência e o êxito dos alunos.

A fim de preservar a identidade e os dados pessoais destes 10 alunos, utilizamos a nomenclatura A1, A2 e A3 para os que se encontram no grupo "A" e B1, B2, B3, B4, B5, B6 e B7 para os do grupo "B".

\section{Cotas para acesso ao ensino técnico de nível médio e sua incidência na permanência e no êxito do aluno}

Nos dados coletados a partir do instrumento aplicado, 60\% da amostra da pesquisa se autodeclarou pardos e, $40 \%$, pretos. Nenhum indígena foi identifica- 
do quando observamos os dados do sistema ou via respostas do questionário. No Quadro 3, a seguir, mostramos excertos das respostas que os alunos deram, ao justificarem a razão por que se autodeclararam pardos ou pretos.

Quadro 3 - Respostas do questionário

\begin{tabular}{|l|l|l|}
\hline Informante & Autodeclaração & \\
\hline B7 & Preto & "Pela cor da minha pele." \\
\hline B4 & Pardo & - \\
\hline B2 & Preto & $\begin{array}{l}\text { "Me considero negro dado às minhas características e também afirmo que } \\
\text { sou por motivos de preconceito que já sofri." }\end{array}$ \\
\hline A2 & Pardo & "Porque sou uma mistura de cores." \\
\hline B3 & Pardo & "Pois possuo avós pretos, brancos e indígenas." \\
\hline B5 & Preto & "Meus pais, avós, todos somos dessa etinia [sic], com vários descenden- \\
te(sic)."
\end{tabular}

Fonte: elaboração dos autores.

Ao questionarmos o motivo pelo qual os informantes se inscreveram para a cota L4, colocamos, junto à pergunta, as condições de acesso pela cota (proveniente de escola pública, preto/pardo/indígena, independentemente de renda) e percebemos que diversos motivos ensejaram essa participação como cotista. Alguns participantes, como "A2", "B5", "B6" e "B1" se restringiram a responder que tinham esse direito, enquanto outros informantes se aprofundaram um pouco mais.

Ao responder a esta questão, nos parece importante ressaltar algumas informações, como, por exemplo, a de "B7", que justificou ter utilizado a cota "pelo motivo de não sentir segurança na efetividade da educação que recebi (pública) e por julgar válido usar cotas". Já "B2" declarou por que acha as cotas válidas: "tendo em vista que além de disputarmos vagas com estudantes que vem de escolas particulares onde o nível de ensino é superior também existe o fato de que historicamente o negro, pardo e o indígena foram tratados como raças inferiores e isso é refletido até hoje tendo como exemplo a minha turma onde apenas 3 alunos incluindo eu mesmo são negros". 
Podemos perceber que para estes informantes a utilização da cota teve um cunho de mobilidade social.

Ao perguntarmos para os componentes da amostra se acreditavam que sua permanência na escola ocorreu por causa da utilização da cota (Questão 09), 20\% respondeu que não, 50\% que sua permanência é consequência de seus próprios esforços e não em virtude da utilização da cota. Outros $20 \%$, ao contrário, afirmaram que sim, que sua permanência na escola se deu em virtude de ter ingressado pela cota L4 e 10\% que sua permanência se deve à contribuição dos benefícios da assistência estudantil. A maioria julga que sua permanência no IFSul se deve ao próprio esforço, o que, por sua vez, nos conduz a acreditar que os alunos superam as dificuldades, independente da forma de acesso, em busca do êxito estudantil. Nesse ponto, a cota se configura apenas como uma oportunidade.

Sobre o êxito escolar, 50\% dos respondentes afirmam que seu êxito escolar não é decorrente da utilização da cota de ingresso, mas sim de seus próprios esforços. Logo, verificamos, através das respostas, que a busca pela superação das dificuldades tem contribuído para o êxito escolar já que $40 \%$ respondeu de forma afirmativa, justificando de formas diferentes.

Contudo, percebemos que, embora a maioria tenha ratificado que seu êxito é decorrente dos seus próprios esforços, grande parte dos informantes (40\%) atribuiu a sua conquista ao fato de ter ingressado pela cota L4, seja pela possibilidade de oportunidades - "[...] porque a concorrência era grande [...]", declarou B5 -, seja por compensar um ensino fundamental (público) deficitário - e "se não tivesse utilizado cotas, [...] não teria adentrado no instituto devido a [...]antiga escola (pública) ter o ensino muito fraco", falou B6 -, seja pela concorrência ou por uma fase de vida difícil - "porque quando entrei passava por uma fase delicada", contou-nos A4. Em nenhum momento os alunos que ingressaram por uma cota que é racial atribuíram a este fato qualquer circunstância vinculada diretamente a racismo ou qualquer preconceito explícito ou ainda à reparação social.

A outra pergunta do questionário, que inqueria se a utilização do(s) benefício(s) da AE contribuía(m) para a permanência na escola, os do grupo "A" (constituído pelos alunos que utilizam ou já utilizaram algum benefício) responderam que "os benefícios ajudam bastante" (A1) e que "pelo fato de ter uma renda baixa e não pode conter os gastos com o instituto, tem sido de grande ajuda os beneficios e tem influenciado na minha permanência no Campus" (A2).

Estas duas respostas que comentamos são extratos que têm paralelos nas demais declarações, ou seja, todos os integrantes do grupo "A" consideram que 
a utilização dos benefícios da $\mathrm{AE}$ contribuiu para a sua permanência na escola. Desta maneira, é possível inferir que, pelo baixo poder aquisitivo que possuem e pela percepção do benefício, esses alunos conseguiram permanecer na escola. De forma contrária, a totalidade do grupo "B", por não utilizar benefícios da AE, responderam "não" ao questionamento. Assim, podemos notar a disparidade de necessidade entre os grupos e também a relevância da prestação desses benefícios àqueles que possuem menor poder aquisitivo. Disto depreende-se a conjectura de que, se não fossem esses benefícios, o índice de evasão dos alunos do grupo "A" poderia aumentar.

A partir disso, pudemos concluir que a incidência da utilização de cotas na permanência e êxito do aluno merece ser subdividida em duas etapas. Na primeira, no tocante à permanência, observamos que os participantes da pesquisa (dos grupos "A" e "B"), em sua maioria, atribuem a permanência aos próprios esforços despendidos nas dificuldades durante a trajetória estudantil. Já em relação à utilização dos benefícios da $\mathrm{AE}$, que a totalidade de alunos do grupo "A" considera como sendo importante para a permanência na escola, e pudemos inferir que foi quase fundamental para que continuassem estudando, evitando assim a evasão.

\section{Considerações finais}

Em que pese a pesquisa ter sido realizada referente ao ingresso para ao ano letivo de 2014, a relevância e atualidade da temática é pertinente, já que buscou verificar como se deu a política de cotas em seu primeiro momento na instituição, ou seja, tão logo se deu a vigência da lei regulamentadora. Além de elucidar aquele momento que a instituição vivia, o estudo vem como forma de subsídio para outros que desejem analisar a temática por completo, realizando uma retrospectiva da implementação das cotas até a atualidade, bem como as questões de permanência adotadas.

O baixo número de candidatos que optou por concorrer por esta forma de ingresso nos indicou, em um primeiro olhar, a pouca divulgação dessa forma de ingresso. No entanto, destacamos que o IFSul foi um dos precursores no oferecimento de ingresso via cotas, já que a legislação do ano de 2012 permitia que as instituições de ensino se valessem do prazo de 04 anos para implementação e o IFSul, tão logo na abertura do processo seletivo seguinte ao da vigência da lei, já adotou esta prática, enquanto outros aguardaram o implemento do prazo para então oferecer o ingresso por meio das cotas. 
As ações afirmativas são consideradas um instrumento de correção pelo "Estado" no sentido de recobrar direitos fundamentais de pessoas que se encontram em desvantagem e/ou desigualdade social, e, por isso, concluímos que objetivam garantir a igualdade e a isonomia entre as pessoas. No caso do IFSul, campus Pelotas, com base na análise das ações promovidas pela escola e com aporte nas respostas da amostra referente ao questionário aplicado, concluímos que as cotas, como meio de acesso, podem promover uma "pseudo" mobilidade social. Isso porque alguns informantes se veem com a necessidade de tratamento diferenciado para conseguir ter acesso a uma educação de melhor qualidade. Assim, a utilização da cota não vem como estrutura que aponte disparidade social ${ }^{16}$, e sim como um elemento essencial à promoção de um "direito constitucional".

No tocante à permanência, verificamos que, no campus Pelotas do IFSul, na época da pesquisa, as ações afirmativas se restringem às adotadas pela assistência estudantil e também, com base nas informações coletadas da amostra, à assistência médica, psicológica e odontológica, que constituem medidas que promovem a manutenção dos alunos no espaço escolar. Não nos deparamos com contribuição, durante a pesquisa, dos alunos na criação, elaboração ou melhoramento dessas ações, o que poderia ser uma temática a ser levantada pelo campus na medida em que traz para perto aqueles que necessitam de alguma ajuda para permanecer estudando. No entanto, observamos que em 2017 foi divulgado o Plano Estratégico Institucional de Permanência e Êxito dos Estudantes do IFSul, o qual auxilia nas medidas que evitam a evasão e fracasso escolar.

Assim, a cota de acesso, pura e estritamente como ação afirmativa, não é fator vinculante à permanência desse indivíduo. Em que pese toda a amostra ter ingressado pela cota L4, a maioria entende que sua permanência é decorrente de seu esforço como estudante, sendo esse meio apenas uma oportunidade de acesso, mas não de permanência na escola ou que enseje tratamento diferenciado para a sua manutenção.

Neste caso, a permanência segue atrelada a fatores como serviços de saúde prestados pela instituição e aos benefícios da assistência estudantil que, por sua vez, está intimamente ligada ao baixo poder aquisitivo dos sujeitos que os utilizam. Logo, esses indivíduos não se enxergam como ocupantes da posição social que necessita da cota para permanência, e sim, apenas para o acesso. 


\section{Notas}

1 Informação obtida através do sítio do IFSul. Disponível em: http://portal2.ifsul.edu.br/index.php?option=com_content\&view=article\&id=1387\%3Aassistencia-estudanil-e-tema-de-capacitacao-\&catid=9\%3Ainstituto-federal-sul-rio-grandense\&Itemid=1. Acesso em: 28 nov. 2016.

2 O Instituto Federal Sul-Rio-Grandense, por ser uma instituição da Rede Federal de Educação Técnica e Tecnológica, dispõe de uma educação híbrida, ofertando ensino de nível médio Técnico, Superior e de Pós-Graduação stricto e lato sensu.

3 Entendido, nesta pesquisa, como conclusão de etapas: por disciplina, por semestre e por curso.

4 Entendido, nesta pesquisa, como apenas não evadido ou concluinte. Seria o ato de o aluno perseverar, continuar, não desistir de seus estudos, obtendo êxito ou não.

5 Optamos pela busca em um período longo, de 2005 a 2016, tendo em vista que, ao realizarmos busca em períodos mais breves e próximos a 2016, encontramos poucos trabalhos e, como consideramos a temática da pesquisa importante, vimos, por bem, aumentarmos o período para que conseguíssemos mais trabalhos que pudessem subsidiar nossa pesquisa.

6 A Lei no 9.394/1996 surge para estabelecer as diretrizes e bases da educação nacional. Estabelece que a educação abrange os processos formativos que se desenvolvem na vida familiar, na convivência humana, no trabalho, nas instituições de ensino e pesquisa, nos movimentos sociais e organizações da sociedade civil e nas manifestações culturais. A lei em questão disciplina a educação escolar, que se desenvolve, predominantemente, por meio do ensino, em instituições próprias (BRASIL, 1996).

7 Art.14, II, Portaria Normativa no ${ }^{\circ}$ 18/2012.

8 A da Organização Didática da Educação Básica, Profissional e Superior de Graduação do IFSul está disponível em: http://www.ifsul.edu.br/regulamento-da-atividade-docente/item/113-organizacao-didatica. Acesso em: 19 set. 2016.

9 O regimento interno e o regimento geral do IFSul estão disponíveis em: http://www.ifsul.edu.br/regimento-geral. Acesso em: 02 ago. 2016.

${ }^{10}$ A Política de Assistência Estudantil do IFSul está disponível em: http://www.ifsul.edu.br/assistencia-estudantil-ifsul/documentos-assistencia/item/101-assistencia-estudantil. Acesso em: 17 set. 2016.

${ }^{11}$ O Regimento da Câmara de Assistência Estudantil está disponível em: http://www.ifsul.edu.br/assistencia-estudantil-ifsul/documentos-assistencia/item/101-assistencia-estudantil. Acesso em: 22 set. 2016.

12 O Plano Estratégico Institucional de Permanência e Êxito dos Estudantes do IFSul foi publicado em 2017, e está disponível em: http://www.ifsul.edu.br/component/k2/item/download/14547_39ae8a4a058847c5a9d3d8f377cf4181. Acesso em: 01 out. 2020.

13 Disponível em: http://pelotas.ifsul.edu.br/ensino/servico-de-psicologia. Acesso em: 15 maio 2017.

${ }^{14}$ Disponível em: http://www.ifsul.edu.br/mapa. Acesso em: 08 abr. 2017.

${ }^{15} \mathrm{O}$ sistema Q-Acadêmico, de propriedade da Qualidata, conforme http://www2.qualidata.com.br/q_academico.htm, é uma ferramenta de gestão acadêmica que possibilita, em um universo de informações e base de dados, que sejam produzidos de relatórios e estatísticas. Além disso, fornece diversos dados relevantes para a Instituição com o cadastro dos alunos e informações acadêmicas destes. Acesso em: 16 maio 2017.

${ }^{16}$ Entendida nessa pesquisa como desigualdade social e/ou econômica, podendo ser decorrente de má distribuição de recursos, escassez de investimentos em políticas sociais, falta de educação básica de boa qualidade, etc.

\section{Referências}

AMABILE, A. E. de N. Políticas Públicas. In: CASTRO, L. F. de; GONTIJO, C. R. B.; AMABILE, A. E. de N. (org.). Dicionário de Políticas Públicas. Barbacena: EdUEMG, 2012.

BRASIL. CNE/CEB. Resolução $n^{\circ}$ 6, de 20 de setembro de 2012. Define Diretrizes Curriculares Nacionais para a Educação Profissional Técnica de Nível Médio. Disponível em: http://portal. 
mec.gov.br/index.php?option=com_docman\&view=download\&alias=11663-rceb006-12-pdf\&category_slug=setembro-2012-pdf\&Itemid=30192 Acesso em 30 set. 2020.

BRASIL. Constituição (1988). Constituição da República Federativa do Brasil. Brasília, DF: Senado Federal, 1988.

BRASIL. Lei n. 9.394, de 20 de dezembro de 1996. Diário Oficial da República Federativa do Brasil, Brasília, DF, n. 248, p. 27833, 23 dez.1996. Seção 1.

BRASIL. Lei n. 12.711, de 29 de agosto de 2012. Diário Oficial da República Federativa do Brasil, Brasília, DF, n. 169, p. 1, 30 ago. 2012. Seção 1.

BRASIL. Lei n. 13.415, de 16 de fevereiro de 2017. Diário Oficial da República Federativa do Brasil, Brasília, DF, n. 35, p. 1, 17 fev. 2017. Seção 1.

BRASIL. Decreto no 7.824, de 11 de outubro de 2012. Diário Oficial da República Federativa do Brasil, Brasília, DF, n. 199, p. 6, 15 out. 2012. Seção 1.

BRASIL. MEC. Portaria Normativa nํ18, de 11 de outubro de 2012. Diário Oficial da República Federativa do Brasil, Brasília, DF, n. 199, p. 16, 15 out. 2012. Seção 1.

BRASIL. MEC. Portaria Normativa n⿳o 09, de 05 de maio de 2017. Diário Oficial da República Federativa do Brasil, Brasília, DF, n. 86, p. 29, 08 mai. 2017. Seção 1.

BRASIL. MEC. Portaria 389, de 09 de maio de 2013. Diário Oficial da República Federativa do Brasil, Brasília, DF, n. 90, p. 12, 13 mai. 2013. Seção 1.

BRASIL. Lei n. 13.005, de 25 de junho de 2014. Diário Oficial da República Federativa do Brasil, Brasília, DF, n. 120-A, p. 1, 26 jun. 2014. Edição Extra.

CHARLOT, Bernard. Relação com o Saber, Formação de Professores e Globalização. Edição Digital. Artmed, 2005.

DENZIN, N. K.; LINCOLN, Y. O planejamento da pesquisa qualitativa: teorias e abordagens. 2 ed. Porto Alegre: ARTMED, 2006.

FERNANDES, F.; LUFT, C. P. Dicionário de sinônimos e antônimos da língua portuguesa. 43 ed. São Paulo: Globo 2005.

FONSECA, J. D. Políticas públicas e ações afirmativas. São Paulo: Selo Negro, 2009.

GOODE, W. J.; HATT, P. K. Métodos em pesquisa social. 2. ed. São Paulo: Nacional, 1968.

GOMES, J. B. Ações afirmativas: aspectos jurídicos. In: SEYFERTH, G. et al. (org.). Racismo no Brasil. São Paulo: Petrópolis; ABONG, 2002.

GOMES, J. B. O debate constitucional sobre ações afirmativas. In: SANTOS, R. E. dos; LOBATO, F. (org.). Ações afirmativas: políticas públicas contra as desigualdades raciais. Rio de Janeiro: DP\&A, 2003. p. 15-57.

GOMES, J. B. A Recepção do Instituto da Ação Afirmativa pelo Direito Constitucional Brasileiro. In: SANTOS, S. A. dos (org.). Ações Afirmativas e Combate ao Racismo nas Américas. Edição Eletrônica. Brasília, DF: Ministério da Educação: UNESCO 2005. p. 47-82.

IVO, A. B. L. Dicionário temático desenvolvimento e questão social: 81 problemáticas contemporâneas. Salvador: Fapesb, 2013. 
IFSUL. Instituto Federal de Educação Ciência e Tecnologia Sul-rio-grandense. Edital 191 / 2013. Pelotas: IFSUL-DES, 2013.

IFSUL. Instituto Federal Sul-rio-grandense. Plano Estratégico Institucional de Permanência e $\hat{E}$ xito dos Estudantes do IFSul. Pelotas: IFSUL-PROEN, 2017.

MARCONI, M. A.; LAKATOS, E. M. Fundamentos de metodologia científica. 6. ed. São Paulo: Atlas, 2005.

BRASIL. MEC. Portaria Interministerial no 4, de 06 de maio de 2016. Disponível em: http:// pesquisa.in.gov.br/imprensa/jsp/visualiza/index.jsp?data=09/05/2016\&jornal=1\&pagina=23\&totalArquivos=216. Acesso em: 1 out. 2020.

BRASIL. MEC. Portaria Normativa nº 09, de 05 de maio de 2017. Disponível em: http://pesquisa.in.gov.br/imprensa/jsp/visualiza/index.jsp?data=08/05/2017\&jornal=1\&pagina=29\&totalArquivos=128. Acesso em: 1 out. 2020.

PIOVESAN, F. Ações Afirmativas sob a perspectiva dos Direitos Humanos. In: SANTOS, S. A. dos (org.). Ações afirmativas e combate ao racismo nas Américas. Edição Eletrônica. Brasília: Ministério da Educação; UNESCO, 2005. p. 35-43.

YIN, Robert. Estudo de caso: planejamento e métodos. 5. ed. Porto Alegre: Bookman, 2015. 